\title{
Correlation Between Triglyceride-Glucose Index and The Clinical Severity of Acute Thrombotic Stroke
}

\author{
Shita Febriana ${ }^{\mathrm{a}}$, Mohammad Saiful Ardhi ${ }^{\text {b* }}$ \\ a official email address: burhanonline@gmail.com

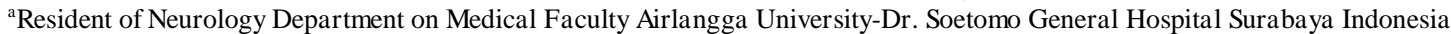 \\ ${ }^{\mathrm{b}}$ Staff of Neurovascular Division of Neurology Department on Medical Faculty Airlangga University-Dr. Soetomo General Hospital \\ Surabaya Indonesia
}

\section{Abstract}

Stroke is a disease that become a problem in the world, because it is the majority cause of death after heart disease. Risk factors for stroke such as hypertension, smoking, diabetes mellitus, dyslipidemia can cause a thrombotic process that begins with damage to the endothelial lining of blood vessels. Hypertriglyceridemia and hyperglycemia are common risk factors for stroke.

There are various mechanisms that cause stroke, one of which is insulin resistance. This insulin resistance can initiate the atherosclerotic process, which if it occurs in the brain can cause a thrombotic stroke. A simple and easy method of measuring insulin resistance is to assess the glucose triglyceride index (tyg index). The wider the atherosclerotic process in the blood vessels of the brain, the more severe the stroke patient will be. Stroke severity was assessed by the National Institutes of Health Stroke Scale (NIHSS). The NIHSS has several degrees of severity where the outcome is often used.

This study assessed the relationship between the glucose triglyceride index and the severity of thrombotic stroke as assessed by the NIHSS. The results obtained from this study were significant with $\mathrm{p}=0.022$ $(\mathrm{p}<0.05)$. However, this relationship is weakly correlated with a correlation coefficient of 0.283 .

Keywords: tyg index;nihss; thrombotic stroke

\section{Introduction}

After ischemic heart disease (14.8\% of all deaths) stroke is the second most common cause of death worldwide (11.8\% of all deaths). Stroke is a serious problem in Asia, with the majority consisting of developing economies. Death due to stroke is higher in Asia compared to Western Europe, America or Australasia (Venketasubramanian N et al, 2017). Based on basic health research (RISKESDAS) in 2018, the prevalence of stroke in Indonesia was 10.9 per mil, an increase from 2013 with a prevalence of 7 per mil (Riskesdas, 2018).

Insulin resistance is one of the risk factors for stroke, which is characterized by hypertriglyceridemia and hyperglycemia. Insulin resistance can develop to thrombotic stroke through the formation of atherosclerosis, 
increases platelet adhesion, activation and aggregation, induces hemodynamic disturbances. They exacerbate thrombotic stroke damage and increases the role of modifiable stroke risk factors, which lead to ischemic stroke (Zhou et al, 2020).

The triglyceride-glucose index (TyG), which was measured by using fasting triglycerides and fasting blood sugar recently has been proposed as an insulin resistance simple marker. TyG index showed a significant correlation with the hyperinsulinermic euglycemic test and homeostatic model assessment for insulin resistance (HOMA-IR) (Zhou et al, 2020).

Although previous studies have shown that the TyG index is associated with carotid atherosclerosis, coronary artery calcification, coronary artery stenosis and a high risk of cardiovascular disease, it is not yet known that the TyG index is associated with the clinical severity of thrombotic stroke patients. One of the assessments used to measure neurological deficits in stroke patients is the National Institutes of Health Stroke Scale (NIHSS). The NIHSS scale has several degrees of severity where the outcome is often used, where scores $<5$ are mild, 5-14 are moderate, 5-25 are severe, and > 25 are very severe. Therefore, this study aims to explore the relationship between the TyG index and the degree of clinical severity in acute thrombotic stroke patients in the neurology department of Dr. Soetomo General Hospital.

\section{Methods}

This research is an analytic observational with a retrospective cross-sectional design using medical record data. The targeted population of this study were all patients with acute thrombotic stroke in March 2019 March 2020. The research material was medical records of acute thrombotic stroke patients who were treated in Dr. Soetomo General Hospital in the period March 2019 to March 2020. The inclusion criteria for this study were: first attack stroke, onset $<72$ hours and age $>18$ years. While the exclusion criteria were: liver disorders, patients with coronary heart disease, infections, history of malignancy, IV thrombolysis therapy and incomplete medical records. After that, patients were assessed for triglycerides, fasting blood glucose and NIHSS at the time of initial hospital admission. Then the glucose triglyceride index was assessed using the following formula: $\ln [($ triglycerides $(\mathrm{mg} / \mathrm{dl}) \mathrm{x}$ fasting plasma glucose $(\mathrm{mg} / \mathrm{dl})] / 2$.

\section{Data analysis}

The data obtained from the data collection sheet will be analyzed. Data analysis using SPSS version 25.0 software. To control for confounding variables, stratification analysis was used for each variable. The relationship between the glucose triglyceride index and the clinical severity of acute thrombotic stroke was analyzed using the Pearson correlation statistical test, if the data were normally distributed. If the data is not normally distributed, the data will be tested with the Spearman correlation.

\section{Result}

\subsection{Demographic, clinical assessment}

The research subjects were acute thrombotic stroke patients who were treated in the Nerve inpatient room of acute thrombotic stroke patients at Dr.Soetomo Hospital Surabaya from April 2019 to February 2020 by means of total sampling that met the inclusion and exclusion criteria. The data used for this study came from the medical record data of RSUD Dr. Soetomo Surabaya. The data taken in the form of demographic data in the form of age, gender, hypertension, results of examination of lipid profiles and blood sugar. From all medical records that were examined, 65 research subjects were obtained in the form of medical records that met the inclusion criteria and exclusion criteria that had been determined.

Overall research subjects analyzed in this study were 65 patients with acute thrombotic stroke. 
Demographic characteristics based on age showed that the youngest age of thrombotic stroke patients in this study was 45 years old and the oldest was 79 years old, with a mean age of 59.9 years of research subjects. Based on gender, male subjects were 34 subjects (52.3\%), while female subjects were 31 subjects (47.7\%).

Clinical characteristics of research subjects included smoking status, history of hypertension, family history of Diabetes Mellitus, severity of stroke, lipid profile and fasting blood sugar levels. In this study, as many as 28 people $(43.8 \%)$ were smokers and 37 people $(56.9 \%)$ did not smoke. Patients with a history of hypertension as many as 45 people $(69.2 \%)$, while those without a history of hypertension were 10 people (23.5\%). Subjects who had a history of diabetes mellitus were 17 people $(26.15 \%)$, while 48 people $(73.85 \%)$ did not have a history of diabetes mellitus. Patients with mild thrombotic stroke as many as 25 people $(38.5 \%)$, while patients with moderate-severe acute thrombotic stroke as many as 40 people $(61.5 \%)$.

Table 1. Demographic Characteristics

\begin{tabular}{lll}
\hline $\begin{array}{l}\text { Demographic } \\
\text { Characteristics }\end{array}$ & Total & Precentage \\
\hline $\begin{array}{l}\text { Gender } \\
\text { Male }\end{array}$ & 34 & $52,3 \%$ \\
Female & 31 & $47,7 \%$ \\
Age & 0 & 0 \\
$29-39$ years & 28 & $43 \%$ \\
$40-59$ years & 37 & $57 \%$ \\
$\geq 60$ years & &
\end{tabular}

History

Diabetes Mellitus

$\begin{array}{lll}\text { Yes } & 17 & 26,15 \% \\ \text { No } & 48 & 73,85 \%\end{array}$

Hypertension

$\begin{array}{lll}\text { Yes } & 45 & 69,2 \% \\ \text { No } & 20 & 30,8 \%\end{array}$

Smoking

$\begin{array}{lll}\text { Yes } & 28 & 43,8 \% \\ \text { No } & 37 & 56,9 \%\end{array}$

NIHSS

$\begin{array}{lll}\text { Mild } & 25 & 38,5 \% \\ \text { Moderate } & 38 & 58,5 \% \\ \text { Severe } & 2 & 3 \%\end{array}$

\subsection{Statistical analysis}

The data obtained from the data collection sheet will be analyzed. Data analysis using SPSS software version 25.0. Firstly, data analysed with descriptive study to asses the minimum, maximum, mean and 
standard deviation of the variables (table2). To control for confounding variables, stratification analysis was used for each variable. The relationship between the glucose triglyceride index and the clinical severity of acute thrombotic stroke was analyzed using the Pearson correlation statistical test, if the data were normally distributed. If the data is not normally distributed, the data will be tested with the Spearman correlation.

Table 2. Value of variables

\begin{tabular}{lllll}
\hline & Minimum & Maximum & Mean & Std. Deviation \\
\hline Tyg Index & 6,01 & 10,58 & 8,8642 &, 79258 \\
NIHSS & 3,00 & 21,00 & 6,8769 & 3,07463 \\
Age & 45,00 & 79,00 & 59,9077 & 8,83127 \\
Systolic & 120,00 & 180,00 & 151,0769 & 16,50029 \\
Diastolic & 80,00 & 110,00 & 90,3077 & 7,69928 \\
Fasting blood glucose & 55,00 & 381,00 & 126,1077 & 58,66220 \\
HDL & 21,00 & 208,00 & 70,8308 & 49,32721 \\
Tryglicerid & 62,00 & 356,00 & 140,0769 & 70,23405 \\
LDL & 11,00 & 236,00 & 117,3231 & 43,74611 \\
Total Cholesterol & 65,60 & 337,20 & 214,2831 & 60,01074 \\
Hba1C & 4,50 & 95,00 & 8,5000 & 11,13342
\end{tabular}

\section{Discussion}

Atherosclerosis is a thickening and hardening of the walls of blood vessels caused by plaque formation. The plaque that forms comes from lipid accumulation, smooth muscle cell proliferation, necrosis, fibrosis and local inflammation (Wu MY et.al,2017 and Groot E et.al, 2008)

Diabetes mellitus, hypertension, dyslipidemia, smoking can cause a thrombotic process that will damage the endothelial lining of blood vessels (Andjelkovic A et.al, 2019). Healing and controlling the damage is hemostasis. Endothelial peeling can be caused by several things, including rupture of atheromatous plaques (Furie, 2018).

Atherosclerosis process is initiated by irritation of blood vessel walls by accumulation of Advanced Glycation End Products (AGEs) especially in conditions of hyperlipidemia, hypertension, hyperglycemia (Chen X et.al, 2013). This accumulation causes endothelial dysfunction through activation of several cytokines and retention of LDL through the macrophage-SR pathway. Endothelial dysfunction will also increase the formation of Reactive Oxygen Species (ROS) and induce local inflammation (Orekhov et.al, 2014).

Endothelial dysfunction is a condition in which arteries lose their ability to dilate and contract due to decreased production of nitric oxide (NO). NO is a substance that regulates vascular tone, blood pressure balance, fibrinolysis, inactive platelets and leukocyte adhesion. Under physiological conditions, tetrahydrobipterin (BH4) regulates NO formation. In conditions of hypertension, hypercholesterolemia, diabetes mellitus and smoking, ROS can oxidize BH4 and result in a decrease in NO (Napoli C et.al, 2006 and Laursen JB et.al, 2001)

One of the risk factors for thrombotic stroke is insulin resistance. Two things that underlie this insulin resistance are hyperglycemia and dyslipidemia. Dyslipidemia, one of which is characterized by an increase in 
triglycerides in insulin resistance due to an increase in liver triglycerides and will be released into the plasma. This is what underlies the assessment of insulin resistance using the glucose triglyceride index. Insulin resistance can cause a lack of insulin that enters the arteriolar smooth muscle cells (hyperglycemia occurs in the plasma), so that the stimulation of nitric oxide release is reduced as a result of vasoconstriction of blood vessels. Fibrinolysis is impaired due to reduced serum tissue plasminogen activator and increased plasminogen activator inhibitor-1 and fibrinogen. High glucose levels are also associated with increased platelet aggregation. Insulin resistance increases the adhesion, activation and aggregation of hypercoagulable platelets. Insulin resistance results in impaired intracellular signaling associated with glucose transport, resulting in metabolic and cellular changes that lead to atherosclerosis. In insulin resistance, which is characterized by hyperglycemia, there can be an inflammatory process caused by oxidative stress mediated by an increase in IL-6 expression resulting in an increase in macrophages, but macrophages here have changed their inflammatory activity, monocyte adhesion to the endothelium has also occurred (Zhou et al, 2020).

Hypertliglycerides also accelerate the process of macrophage and monocyte adhesion in blood vessels mediated by various proinflammatory agents (TNF- $\alpha$, IL1 $\beta$, Monocyte chemotactic protein-1, ICAM-1, MMP-3). The above will cause endothelial dysfunction that can continue to be a process of atherosclerosis in the blood vessels of the brain. This ongoing process of atherosclerosis will cause occlusion of blood vessels, so that neurological deficits can occur. The process of atherosclerosis mediated by insulin resistance is assessed by the TyG index. Meanwhile, neurological deficit/severity was assessed by the NIHSS score (Cominacini L et.al, 1997 and Sakthiswary et.al, 2016)

The relationship between the Tyg index and the NIHSS was assessed by Spearman correlation which showed a significant relationship with $\mathrm{p}=0.022$ ( $\mathrm{p}<0005$, significant). This correlation is a weak correlation with a coefficient of 0.283 . this is an accordance with te research of Zhou,2020, that explained that Tyg index was correlated with degree of severity assesed by NIHSS score.

Several confounding factors were also assessed in this study such as: age, blood pressure, fasting blood sugar, lipid profile. Age, systolic and diastolic pressure were not associated with the NIHSS with a $\mathrm{p}$ value of $0.174 ; 0.483$ and 0.648 . This is in accordance with the research of Rianawati et al who explained that there was no relationship between initial systolic and diastolic blood pressure with NIIHSS with a very weak correlation (Rianawati et.al, 2015)

Lipid profiles such as triglycerides, LDL, HDL, total cholesterol were not associated with the NIHSS with p-values of $0.187 ; 0.438 ; 0.682 ; 0.863$ ( $p>0.05$ ). This is in contrast to research by Bharosay et al. which showed that increased levels of total cholesterol, triglycerides and LDL and low levels of HDL were associated with an increase in NIHSS. This is due to the absence of previous lipid profile data, so it is not possible to determine whether the acute phase reaction can affect lipid profile levels (Bharosay et.al, 2013)

The relationship between fasting blood sugar and NIHSS was significantly correlated with a $\mathrm{p}$ value = 0.027. Therefore, stratification analysis was used to determine this relationship. At low fasting blood sugar $(<126 \mathrm{mg} / \mathrm{dl})$, the relationship between tyg index and NIHSS was not significant ( $\mathrm{p}=0.108)$. Meanwhile, in high fasting blood sugar, the relationship between the tyg index and the NIHSS was not significant $(p=0.386)$. So fasting blood sugar has no effect on the relationship between the tyg index and the NIHSS.

\section{Limitation}

This study has limitations. iin this study the NIHSS assessment was carried out on the onset of the 1st day of stroke, while patients came to the hospital with different stroke onset so that the length of stay was also different when the NIHSS assessment was carried out. This causes each patient to get a different initial management so that it will affect the assessment of the severity of stroke. Assessment of stroke severity is based on the NIHSS value, the NIHSS value on the NIHSS assessment sheet contained in the medical record is assessed by several different people who are not tested for the same assessment, this can affect the NIHSS value used in this study so that it can also affect the assessment of stroke severity patient. 
The other limitations of this study are the data used are medical record data and single center where researchers have tried to exclude factors that affect the glucose triglyceride index value, but it would be better if using primary data where researchers can really control the factors which affects the NIHSS value. This study was conducted in a cross sectional manner which would be better if it was conducted in a cohort that could be followed prospectively. This study also did not differentiate and analyze thrombotic stroke based on its subtype.

\section{References}

Andjelkovic A V., Xiang J, Stamatovic SM, et al. Endothelial Targets in Stroke: Translating Animal Models to Human. Arterioscler Thromb Vasc Biol. 2019;39(11):2240-2247. doi:10.1161/ATVBAHA.119.312816

Bharosay et al. Effect of Lipid Profile Upon Prognosis in Ischemic and Hemorrhagic Stroke.2013

Chen XUE, Pyzik R, Yong A, Striker GE. AGE's in Foods and practical ways to reduce them. J Am Diet Assoc. 2013;110(6):911-916. doi:10.1016/j.jada.2010.03.018.Advanced

Cominacini L, Garbin U, Pasini AF, et al. Antioxidants inhibit the expression of intercellular cell adhesion molecule-1 and vascular cell adhesion molecule-1 induced by oxidized LDL on human umbilical vein endothelial cells. Free Radic Biol Med. 1997;22(12):117-127. doi:10.1016/s0891-5849(96)00271-7

Furie B, Furie BC. Mechanisms of thrombus formation. N Engl J Med. 2008;359(9):938-949. doi:10.1056/NEJMra0801082

Groot E, van Leuven SI, Duivenvoorden R, et al. Measurement of carotid intima-media thickness to assess progression and regression of atherosclerosis. Nat Clin Pract Cardiovasc Med. 2008;5(5):280-288. doi:10.1038/ncpcardio1163

Kimura et al. Atrial Fibrillationas a predictive factor for severity stroke and early death in 15831 patientswith acute ischemicstroke. J Neurosurg Psychiatry

Laursen JB, Somers M, Kurz S, et al. Implications for Interactions Between Peroxynitrite. Circulation. 2001;103:1282-1289.

Napoli C, de Nigris F, Williams-Ignarro S, Pignalosa O, Sica V, Ignarro LJ. Nitric oxide and atherosclerosis: An update. Nitric Oxide Biol Chem. 2006;15(4):265-279. doi:10.1016/j.niox.2006.03.011

Orekhov AN, Bobryshev Y V., Sobenin IA, Melnichenko AA, Chistiakov DA. Modified low density lipoprotein and lipoproteincontaining circulating immune complexes as diagnostic and prognostic biomarkers of atherosclerosis and type 1 diabetes macrovascular disease. Int J Mol Sci. 2014;15(7):12807-12841. doi:10.3390/ijms150712807

Riananwati,S dkk. Hubungan antara tekanan darah pada saat masuk dengan luaran klinis pasien stroke thrombosis akut. Malang Neurology Journal.2015

RISKESDAS. Hasil Utama Riset Kesehatan Dasar. Kementrian Kesehat RI. 2018:1100.http://www.depkes.go.id/resources/download/info-terkini/hasilriskesdas-2018.pdf.

Sakthiswary R, Singh R. Has the median nerve involvement in rheumatoid arthritis been overemphasized? Rev Bras Reumatol. 2017;57(2):122-128. doi:10.1016/j.rbre.2016.09.001

Venketasubramanian N, Yoon BW, Pandian J, Navarro JC. Stroke epidemiology in south, east, and south-east asia: A review. J Stroke. 2017;19(3):286-294.

Wu MY, Li CJ, Hou MF, Chu PY. New insights into the role of inflammation in the pathogenesis of atherosclerosis. Int J Mol Sci. 2017;18(10). doi:10.3390/ijms18102034

Zhou Y, Pan Y, Yan H, et al. Triglyceride Glucose Index and Prognosis of Patients With Ischemic Stroke. Front Neurol. 2020;11(June). doi:10.3389/fneur.2020.00456 
